\title{
How to Interpret Hydrogen Breath Tests
}

\author{
Uday C Ghoshal \\ Department of Gastroenterology, Sanjay Gandhi Postgraduate Institute of Medical Sciences, Lucknow, India
}

Hydrogen breath tests using various substrates like glucose, lactulose, lactose and fructose are being used more and more to diagnose small intestinal bacterial overgrowth (SIBO) and lactose or fructose malabsorption. Though quantitative culture of jejunal aspirate is considered as gold standard for the diagnosis of SIBO, hydrogen breath tests, in spite of their low sensitivity, are popular for their non-invasiveness. Glucose hydrogen breath test is more acceptable for the diagnosis of SIBO as conventionally accepted double-peak criterion on lactulose hydrogen breath test is very insensitive and recently described early-peak criterion is often false positive. Hydrogen breath test is useful to diagnose various types of sugar malabsorption. Technique and interpretation of different hydrogen breath tests are outlined in this review.

(J Neurogastroenterol Motil 2011;17:312-317)

\section{Key Words}

Breath tests; Hydrogen; Intestine, small; Irritable bowel syndrome

\section{Introduction}

Recently, hydrogen breath test (HBT) has become popular in clinical practice as it is useful for diagnosing small intestinal bacterial overgrowth (SIBO) and carbohydrate intolerance such as lactose and fructose malabsorption (Table). ${ }^{1}$ Though quantitative culture of jejunal aspirate is considered as gold standard for the diagnosis of SIBO, HBT is popular as it is non-invasive. ${ }^{1,2}$ In spite of the simplicity of performance, there is lack of uniformity regarding the interpretation of various HBTs. Therefore, technique and interpretation of commonly used HBTs are reviewed here.

\section{Principle of Hydrogen Breath Tests}

In these tests, hydrogen exhaled in the breath is estimated us-

Table. Various Hydrogen Breath Tests Used in Clinical Practice and Their Clinical Utility

\begin{tabular}{lll}
\hline \multicolumn{1}{c}{ Name of the test } & Substrate & Diagnostic utility \\
\hline $\begin{array}{l}\text { Glucose hydrogen breath test } \\
\text { Lactulose hydrogen breath test }\end{array}$ & Glucose & Small intestinal bacterial overgrowth \\
& Lactulose & Estimation of oro-cecal transit time \\
Lactose hydrogen breath test & Small intestinal bacterial overgrowth \\
Fructose hydrogen breath test & Fructose & Lactose malabsorption \\
\hline
\end{tabular}

Received: June 7, 2011 Revised: June 19, 2011 Accepted: June 20, 2011

(c) This is an Open Access article distributed under the terms of the Creative Commons Attribution Non-Commercial License (http://creativecommons. org/licenses/by-nc/3.0) which permits unrestricted non-commercial use, distribution, and reproduction in any medium, provided the original work is properly cited.

*Correspondence: Uday C Ghoshal, MD, DNB, DM, FACG

Additional Professor, Department of Gastroenterology, Sanjay Gandhi Postgraduate Institute of Medical Sciences, Lucknow 226014, India

Financial support: None.

Tel: +91-962-8842456, Fax: +91-522-2668017 (or 2668078), E-mail: udayghoshal@gmail.com

Conflicts of interest: None. 
ing a gas chromatograph. Bacteria, especially anaerobic, colonizing the large bowel in health and small bowel in diseased conditions produce hydrogen by fermentation of unabsorbed carbohydrates. Though small amount of hydrogen is produced from limited amounts of unabsorbed carbohydrate reaching the colon, large amounts of hydrogen may be produced if there is malaborption of carbohydrate in the small intestine allowing larger amount to reach the colon or if there is excess of bacteria in the small bowel. The hydrogen produced by the bacteria is absorbed through the wall of the small or large intestine or both. The hydrogen-containing blood travels to the lungs where the hydrogen is released and exhaled in the breath where it can be measured. About 15\%-30\% people have gut flora that contain Methanobrevibacter smithii, which converts 4 atoms of hydrogen into 1 molecule of methane. ${ }^{3}$ These subjects may not exhale much hydrogen in the breath in spite of having SIBO or carbohydrate malabsorption as excess hydrogen produced in them is converted into methane. Figure 1 summarizes the principle of HBTs.

\section{Patient Preparation}

The subjects are asked to avoid slowly absorbed carbohy- drates (like bread and potato) and fiber the previous night as these would cause delayed excretion of hydrogen in breath. ${ }^{2}$ Cigarette smoking and exercise are avoided 2 hours before and during the test, as hyperventilation can cause changes in breath hydrogen content. ${ }^{2}$ Pro-motility, anti-motility drugs, antibiotics and other drugs that can cause SIBO including proton pump inhibitors should be discontinued before performing breath tests.

\section{Procedure of the Breath Test}

Breath test is performed after overnight fast. Before the test, subjects are asked to brush their teeth and rinse mouth with antiseptic mouth wash and tap water, to eliminate an early hydrogen peak due to action of oral bacteria on test sugars. ${ }^{2}$ End-expiratory breath samples are collected either in bag or syringes. At the start of the test, fasting breath hydrogen is estimated 3 to 4 times and the average of these values is taken as the basal breath hydrogen. Subsequently, the subject ingests a fixed amount of the test sugar (10 g lactulose, $100 \mathrm{~g}$ glucose, $50 \mathrm{~g}$ lactose or $25 \mathrm{~g}$ fructose). All samples of breath are analyzed for hydrogen and methane every 15 minutes for 2 to 4 hours. These values are written on a diary. Special computer softwares are also available to record values of

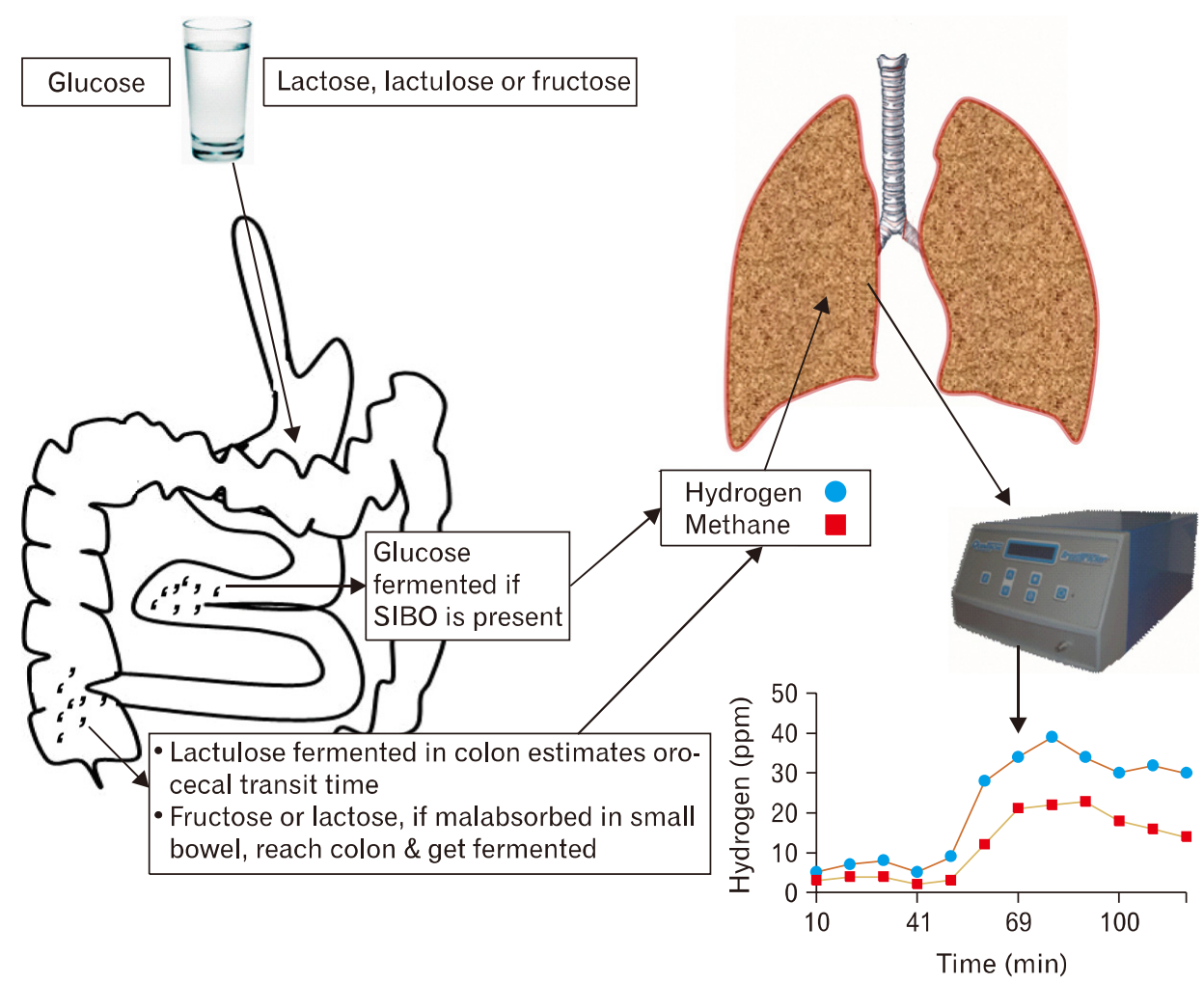

Figure 1. A schematic diagram that shows principle of hydrogen breath test. SIBO, small intestinal bacterial overgrowth; ppm, parts per million. 
the breath tests. Development of symptoms following ingestion of the substrate is also noted. ${ }^{4}$ Lactose tolerance test, which involves estimation of blood sugar in fasting state and 30-minutes after ingestion of lactose, is usually combined with lactose HBT.
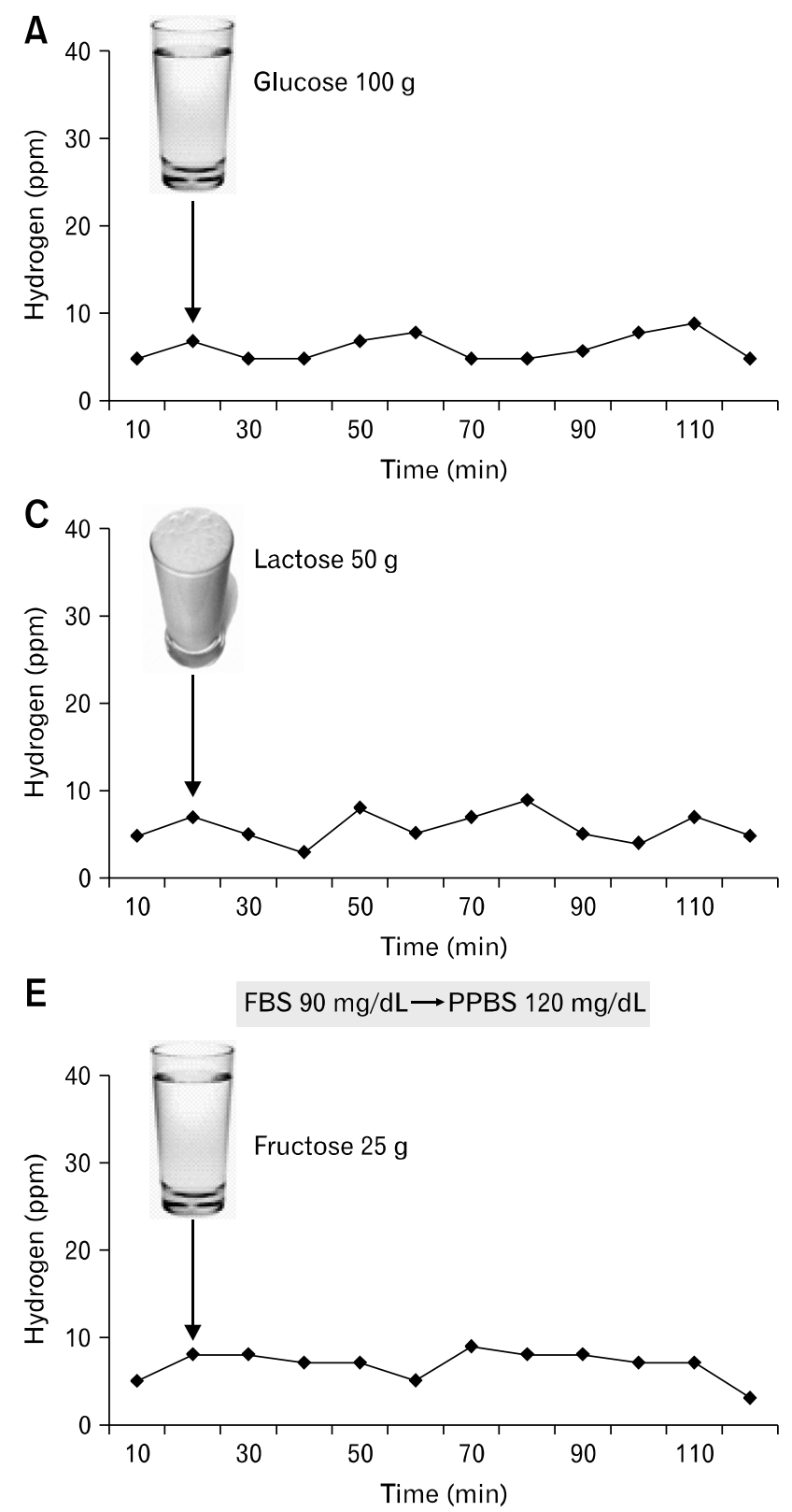

\section{Interpretation of Breath Tests}

Figure 2 shows some typical HBT graphs. HBTs are interpreted as follows.
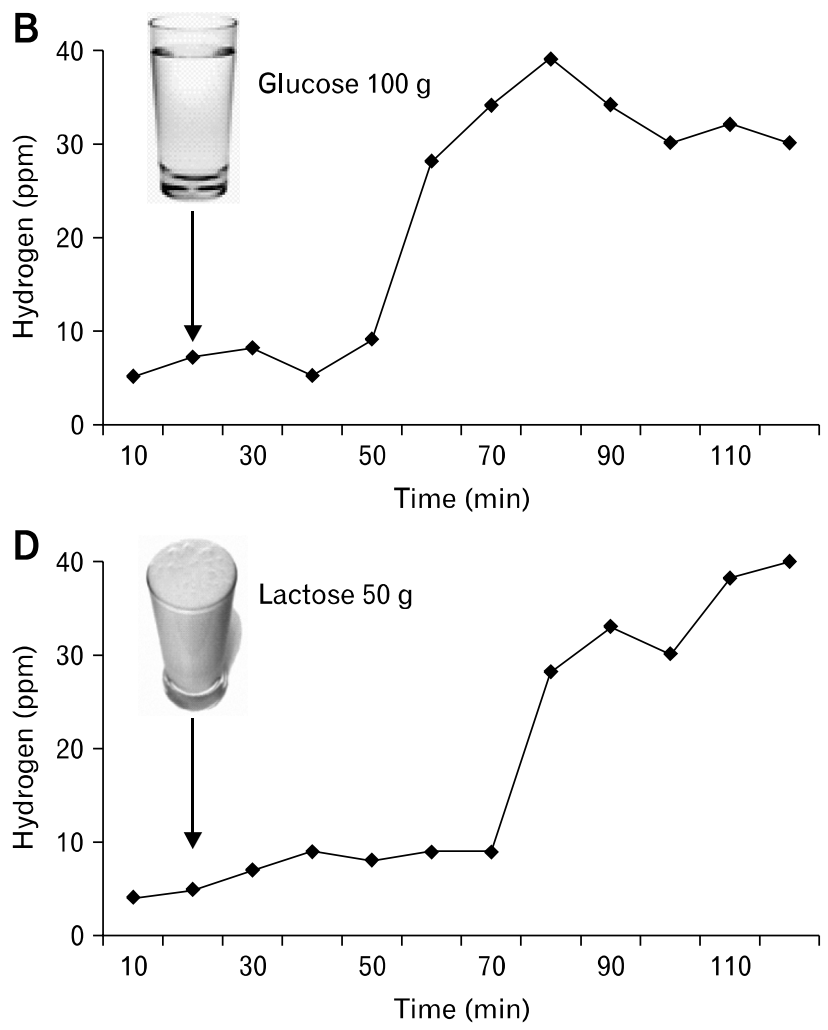

$\mathbf{F}$ FBS $80 \mathrm{mg} / \mathrm{dL} \longrightarrow$ PPBS $90 \mathrm{mg} / \mathrm{dL}$

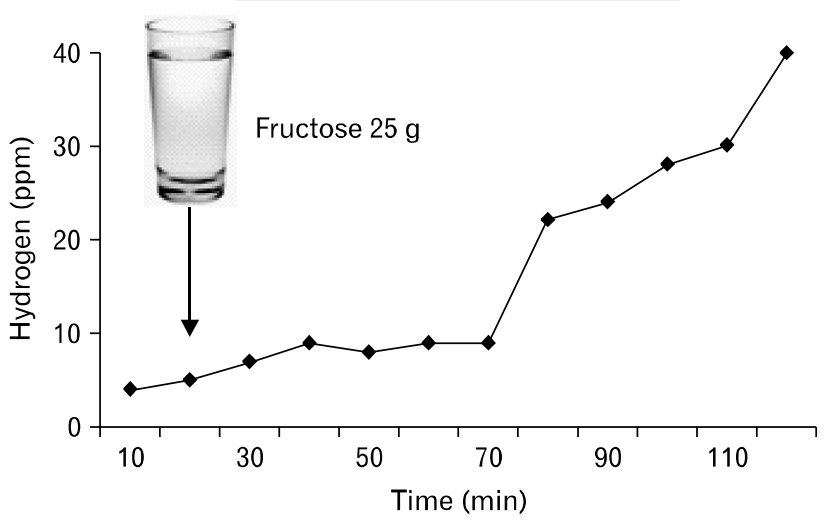

Figure 2. Some typical hydrogen breath test graphs are shown. It shows glucose hydrogen breath test negative for small intestinal bacterial overgrowth (SIBO) (A), glucose hydrogen breath test positive for SIBO (B), lactose hydrogen breath and tolerance test negative for lactose malabsorption (C) and lactose hydrogen breath and tolerance test positive for lactose malabsorption (D). It shows a graph negative for fructose malabsorption (E) and a graph positive for fructose malabsorption (F). ppm, parts per million; FBS, fasting blood sugar; PPBS, post-prandial blood sugar. 


\section{High Basal Breath Hydrogen}

If average basal values of breath hydrogen is more than 16 parts per million (ppm), it is generally considered as a high value. ${ }^{6}$ The substrate may not be administered if basal breath hydrogen is high and the test would be abandoned. In such situation, the test is repeated with proper preparation again. Some investigators considered high basal breath hydrogen to be suggestive of $\mathrm{SIBO}^{7}$ though evidences available are contradictory. ${ }^{6}$

\section{Diagnosis of Small Intestinal Bacterial Overgrowth on Glucose and Lactulose Hydrogen Breath Test}

SIBO is diagnosed on glucose HBT if there is a rise in breath hydrogen by $12 \mathrm{ppm}$ above the basal. The sensitivity and specificity of this criterion to diagnose SIBO are $40 \%$ and $80 \%$, respectively. ${ }^{2}$ Conventionally, double peak in lactulose HBT (one due to SIBO and the other from colon) is considered as diagnostic of SIBO. Sensitivity and specificity of lactulose HBT to diagnose SIBO using this conventional criterion are $31 \%$ and $86 \%$, respectively when considering the quantitative culture of jejunal aspirate (bacterial colony count $\geq 10^{5} \mathrm{CFU} / \mathrm{mL}$ ) as gold standard. $^{2}$

\section{Glucose or Lactulose Hydrogen Breath Test to Diagnose Small Intestinal Bacterial Over- growth?}

A double-peak criteria on lactulose $\mathrm{HBT}$ as mentioned above is only $31 \%$ sensitive to diagnose SIBO. ${ }^{2}$ Pimentel et al ${ }^{8}$ suggested that a rise in breath hydrogen 20 ppm above basal levels within 90 minutes after ingestion of lactulose should be considered as diagnostic of SIBO. This criterion has not been validated. Moreover, it presumes that mouth-to-cecum transit time is always greater than 90 minutes, so that a peak in breath hydrogen within 90 minutes after lactulose ingestion must be due to bacterial fermentation in the small bowel. However, this assumption is not correct. Mouth-to-cecum transit time in Asian populations is often shorter than 90 minutes. For example, in our study, median mouth-to-cecum transit time in 12 healthy Indian subjects was 65 minutes (range 40 to 110 minutes). ${ }^{9}$ In a study of 45 healthy Taiwanese, mean mouth-to-cecum transit time was 85 minutes (standard deviation 37). ${ }^{10}$ Therefore, a large proportion of these healthy subjects would have been diagnosed as having SIBO if Pimentel's criterion had been employed. Hence, lactulose HBT should not be used to diagnose SIBO. Even the double-peak cri- terion to diagnose SIBO on lactulose HBT has lower sensitivity than glucose HBT (31\% vs $40 \%){ }^{2}$ Therefore, glucose HBT should be used for diagnosing SIBO.

\section{Limitations of Hydrogen Breath Test to Diagnose Small Intestinal Bacterial Overgrowth}

There are several limitations of HBT for the diagnosis of SIBO.

(1) HBT with lactulose may be able to diagnose only one-third of patients with SIBO. ${ }^{2}$ Since glucose is absorbed completely in the upper small intestine, it may not be able to diagnose $\mathrm{SIBO}$ of the distal small intestine (ileum). ${ }^{11} \mathrm{~A}$ major problem is that there is no "gold standard" for the diagnosis of SIBO since culture of the bacteria has its own limitations, as only $30 \%$ of gut bacteria are culturable. ${ }^{11}$ However, in our study we have found GHBT to be highly specific for diagnosis of SIBO. ${ }^{2}$ Hence, it is important to realize that GHBT can underestimate but is unlikely to overestimate SIBO.

(2) There may be similarities in the pattern of gas production with SIBO and rapid intestinal transit, thus making distinctions difficult.

(3) Some normal individuals may have slow transit through the small intestine leading to prolonged testing, up to 5 hours and many individuals may not like to undergo such a time consuming procedure.

(4) A proportion of individuals have bacteria that do not produce hydrogen but produce other gases such as methane and hydrogen sulphide; therefore, their SIBO, if present, may not be detected with the HBT. ${ }^{3}$ Estimation of methane may be useful in such situation. There is no commercially available machine currently that measures hydrogen sulphide.

(5) Some individuals may produce a combination of hydrogen and methane. There is much less experience with methane as compared with hydrogen for the diagnosis of SIBO. However, the production of methane is more complex than the production of hydrogen. Therefore, it is not clear if the pattern of methane production after ingestion of sugars can be interpreted in the same way as hydrogen production. Furthermore, all the equipments available in the market for HBTs do not have facilities for estimation of methane. As mentioned above, the equipments that have facilities for estimation of methane as well as hydrogen are superior for HBT. Methane is a marker of constipation. ${ }^{12}$

(6) A positive HBT may not always mean that a patient's symptoms are caused by SIBO. The only way to establish whether the symptoms are caused by SIBO is to treat and eradicate the 
bacteria. If the symptoms disappear, it is likely that SIBO rather than the underlying disease is responsible for the symptoms.

\section{Lactulose Hydrogen Breath Test to Estimate Oro-Cecal Transit Time}

The time interval between ingestion of lactulose and rise in breath hydrogen $20 \mathrm{ppm}$ above basal is a measure of oro-cecal transit time. It is important to note that value of breath hydrogen to diagnose an abnormality is generally higher if fermentation of the substrate occurs in the colon rather than small intestine. For this reason, the cut-off value of hydrogen to estimate oro-cecal transit time, lactose and fructose malabsorption is $20 \mathrm{ppm}$ above basal; in contrast, the cut-off value of hydrogen to diagnose bacterial overgrowth in the small intestine is $12 \mathrm{ppm}$ above basal. Recently, in a study in which lactulose HBT was compared with radio-nuclide scintigraphic method for estimation of oro-cecal transit time, the former was shown to have reasonable accuracy for this purpose. ${ }^{13}$

\section{Lactose Hydrogen Breath test for Diagnosis of Lactose Malabsorption}

Rise in hydrogen by $20 \mathrm{ppm}$ above basal after lactose ingestion is considered as positive lactose HBT. Failure of blood sugar to rise by $20 \mathrm{mg} / \mathrm{dL}$ at 30 minutes after ingestion of lactose is considered as positive lactose tolerance test, which is indicative of lactose malabsorption. ${ }^{4,5}$

There are some issues in the current protocol for lactose HBT. Some data suggest that lactose tolerance test may be as good as or more sensitive than lactose HBT. Lactose dose of 50 $\mathrm{g}$, as suggested in the current protocol, may be too high and non-physiological. This may lead to overestimation of frequency of lactose malabsorption which may not always be clinically important in areas of the world where frequency of the condition is too high. ${ }^{4}$

\section{Interpretation of Fructose Hydrogen Breath Test}

Rise in hydrogen by $20 \mathrm{ppm}$ above basal after fructose ingestion is considered as positive fructose HBT. ${ }^{14}$

\section{Clinical Importance of Breath Gas Profile}

Some data suggest that basal breath hydrogen both in fasting state and following ingestion of a substrate is higher among patients with irritable bowel syndrome, particularly in those with diarrhea-predominant disease than controls. ${ }^{15}$ In contrast, people with constipation may have high methane. ${ }^{3}$ Therefore, hydrogen may be a biomarker for diarrhea and methane of constipation. ${ }^{6,12,15}$ Reduction of methane by rifaximin may improve constipation. ${ }^{12}$ Hydrogen may also contribute to development of abdominal bloating.

\section{Conclusion}

HBTs are easy to perform and are non-invasive. These may be useful to understand abnormal pathophysiology such as SIBO and carbohydrate malabsorption contributing to symptoms in patients presenting with irritable bowel syndrome. It is suggested that uniform criteria should be developed and used for diagnosis of various disorders by HBTs.

\section{References}

1. Lindberg DA. Hydrogen breath testing in adults: what is it and why is it performed? Gastroenterol Nurs 2009;32:19-24.

2. Ghoshal UC, Ghoshal U, Das K, Misra A. Utility of hydrogen breath tests in diagnosis of small intestinal bacterial overgrowth in malabsorption syndrome and its relationship with oro-cecal transit time. Indian J Gastroenterol 2006;25:6-10.

3. Levitt MD, Furne JK, Kuskowski M, Ruddy J. Stability of human methanogenic flora over 35 years and a review of insights obtained from breath methane measurements. Clin Gastroenterol Hepatol 2006;4:123-129.

4. Gupta D, Ghoshal UC, Misra A, Choudhuri G, Singh K. Lactose intolerance in patients with irritable bowel syndrome from northern India: a case-control study. J Gastroenterol Hepatol 2007;22:22612265 .

5. Babu J, Kumar S, Babu P, Prasad JH, Ghoshal UC. Frequency of lactose malabsorption among healthy southern and northern Indian populations by genetic analysis and lactose hydrogen breath and tolerance tests. Am J Clin Nutr 2009;91:140-146.

6. Kumar S, Misra A, Ghoshal UC. Patients with irritable bowel syndrome exhale more hydrogen than healthy subjects in fasting state. J Neurogastroenterol Motil 2010;16:299-305.

7. Pande C, Kumar A, Sarin SK. Small-intestinal bacterial overgrowth in cirrhosis is related to the severity of liver disease. Aliment Pharmacol Ther 2009;29:1273-1281.

8. Pimentel M, Chow EJ, Lin HC. Eradication of small intestinal bacterial overgrowth reduces symptoms of irritable bowel syndrome. Am J Gastroenterol 2000;95:3503-3506.

9. Ghoshal UC, Ghoshal U, Ayyagari A, et al. Tropical sprue is associated with contamination of small bowel with aerobic bacteria and reversible prolongation of orocecal transit time. J Gastroenterol Hepatol 2003;18:540-547.

10. Lu CL, Chen CY, Chang FY, Lee SD. Characteristics of small bowel motility in patients with irritable bowel syndrome and normal humans: an Oriental study. Clin Sci (Lond) 1998;95:165-169. 
11. Lin HC. Small intestinal bacterial overgrowth: a framework for understanding irritable bowel syndrome. JAMA 2004;292:852-858.

12. Ghoshal UC, Srivastava D, Verma A, Misra A. Slow transit constipation associated with excess methane production and its improvement following rifaximin therapy: a case report. J Neurogastroenterol Motil 2011;17:48-51.

13. Yu D, Cheeseman F, Vanner S. Combined oro-caecal scintigraphy and lactulose hydrogen breath testing demonstrate that breath testing detects oro-caecal transit, not small intestinal bacterial overgrowth in patients with IBS. Gut 2011;60:334-340.

14. Gibson PR, Newnman E, Barrett JS, Shepherd SJ, Muir JG. Review article: fructose malabsorption and the bigger picture. Aliment Pharmacol Ther 2007;25:349-363.

15. Ghoshal UC, Kumar S, Mehrotra M, Lakshmi C, Misra A. Frequency of small intestinal bacterial overgrowth in patients with irritable bowel syndrome and chronic non-specific diarrhea. J Neurogastroenterol Motil 2010;16:40-46. 